\title{
CONFERENCIA MAGISTRAL INAUGURACIÓN AÑO ACADÉMICO 2012 FACULTAD DE CIENCIAS JURÍDICAS Y SOCIALES. UNIVERSIDAD DE TALCA, ESCUELA DE DERECHO, CAMPUS SANTIAGO*
}

\section{Alfredo Etcheberry Osthustegi*}

Señor Rector de la Universidad de Talca, Señores miembros de la Junta Directiva de la Universidad, Señora Secretaria General de la Universidad, Señor Decano de la Facultad de Derecho, Señores Profesores de la Facultad,

Estimados estudiantes,

Colegas, amigos, señoras y señores:

Me he sentido profundamente honrado y agradecido cuando la Universidad de Talca, por intermedio de su Decano de la Facultad de Derecho, me invitó a hacer uso de la palabra en la Clase Inaugural del año académico en la Escuela de Derecho de esta Universidad en Santiago.

Lo hago gustoso, porque esto me brinda la oportunidad para, más que dictar una clase o una conferencia, formular ante ustedes, para compartir con ustedes, para pensar con ustedes, algunas reflexiones sobre lo que es esta profesión de abogado, a la que ustedes, llenos de ideales y de ilusiones, aspiran a llegar, y en la que yo, tal vez con algunas ilusiones menos, pero con los mismos ideales intactos, llevo varias décadas de ejercicio.

Ante todo, permítanme decirles que desde estudiante he cultivado con cariño y pasión el derecho; que nunca me he arrepentido de ello, aun en épocas sombrías en que el derecho estaba ahogado por la atmósfera enrarecida de los decretos-leyes; que el recuerdo es grato, que el balance es positivo y que si por virtud sobrenatural pudiera retroceder en el tiempo a las etapas de la vida en que se toman las grandes decisiones y en que se hace un examen del camino

\footnotetext{
* Conferencia dictada el día 30 de marzo de 2012 en la Inauguración del Año Académico de la Primera Generación de estudiantes de la Escuela de Derecho de la Facultad de Ciencias Jurídicas y Sociales de la Universidad de Talca en el Campus Santiago. Colaboración recibida el 2 de abril y aprobada el 20 de abril de 2012.

** Abogado; Profesor de Derecho Penal U. de Chile; Dr. h.c. U. de Talca. Correo electrónico: Imcampos@etcheberry.com.
} 
ya recorrido y se está todavía a tiempo para cambiar de rumbo y enmendar las rutas equivocadas, no vacilaría en emprender de nuevo el camino del derecho o en perseverar por el camino.

Alguien podría pensar, y con cierta alarma: ¿Otra escuela de Derecho más, cuando en Chile ya hay tantas? ¿No se leen con frecuencia en la prensa artículos en que se expresa preocupación sobre el número de abogados en Chile y se señalan críticas por la deficiente preparación con que muchos de ellos egresan de tantas escuelas nuevas? ¿Será esto verdad, queridos estudiantes?

Sobre la calidad de la preparación académica y humana que ustedes van a recibir, no albergo cuidado alguno. Ingresan ustedes a la Universidad de Talca, descendiente directa de la Universidad de Chile, en la cual yo mismo me formé y en la cual he dictado cátedra por muchos años, y que al adquirir existencia independiente, en vez de languidecer o vegetar, ha brotado como un retoño lleno de empuje, con más de 8.000 alumnos de pre y posgrado, y una acción vigorosa y cada día renovada de compromiso con la excelencia académica y con la realidad nacional. Su Facultad de Derecho goza de merecida y alta reputación y en Santiago ha estado ya desde hace tiempo representada en forma sobresaliente por su Centro de Estudios de Derecho Penal, al cual las autoridades universitarias muy sabiamente han sabido dotar de los recursos necesarios para impartir en forma regular la enseñanza y dirigir la investigación; lo han dotado de una magnífica biblioteca y de cómodas y modernas instalaciones, en que se desarrollan cursos y conferencias merecidamente concurridos. A la Universidad de Talca debemos agradecer también el flujo continuo de visitas de ilustres catedráticos extranjeros que han venido a compartir con nosotros la plenitud del conocimiento intelectual. No puede caber duda, entonces, del alto nivel académico que encontrarán ustedes en esta casa de estudios.

En cuanto al supuesto exceso de abogados en Chile, es un tema sobre el que volveremos más adelante, pero puedo adelantar una reflexión. Tal vez haya demasiados abogados para quienes actualmente solicitan sus servicios, pero en relación con quienes realmente los necesitan, no los hay en número suficiente. Cuando yo hice mi práctica profesional en la Corporación (o Servicio, como se llamaba entonces) de Asistencia Judicial, mi grupo se componía de cuatro postulantes egresados de derecho, los cuatro bajo la dirección y vigilancia de un solo abogado, y a cada uno de nosotros se les asignaba la atención de alrededor de 100 casos. Yo personalmente alcancé a tramitar 120. Eso hace un total de alrededor de 400 causas atendidas por un solo abogado titulado. $\mathrm{Si}$ pensamos que razonable y responsablemente un abogado no puede atender en forma paralela más allá de 25 ó 30 casos, queda a la vista, no la escasez, sino al revés, la carencia del número de abogados necesarios para atender a quienes necesitan sus servicios, pero no pueden costearlos. Y si bien eso ocurrió hace muchos años, tengo dos nietos, titulados de abogado hace muy poco, que me 
han confirmado que esas cifras son muy parecidas a las que se presentan en los actuales consultorios gratuitos. De todos modos, como he dicho, volveremos sobre ello.

Dicho esto, entremos en materia.

Nuestra primera reflexión será: ¿Qué se necesita para ser abogado?

Por lo pronto, en nuestra opinión, en el terreno intelectual sólo se necesita una inteligencia normal, no deficiente, por cierto, pero tampoco superdotada.

Alguien ha dicho, con cierto ingenio, pero con mucha dosis de verdad: "Las leyes son como el ajedrez: todo el mundo puede aprenderlo, pero no todos llegan a jugarlo bien".

¿Qué se necesita, entonces, para llegar a ser un buen abogado, o como se diría más coloquialmente, "tener pasta" de abogado?

Descarten ustedes, si es que no lo han hecho ya, la idea muy difundida entre quienes no están vinculados a nuestra profesión, de que la oratoria y la memoria hacen un buen abogado. Ello no es verdad, particularmente entre nosotros, donde las características de nuestro proceso han reducido mucho el papel que la oratoria tradicionalmente ha tenido en el ejercicio de la profesión de abogado. La memoria es sin duda una ayuda preciosa, de la cual no debe nunca renegarse, ni debe ser nunca menospreciada, pero es solamente eso: una ayuda. También el abogado debe saber expresarse, eso sí, pero no es necesario y hasta puede ser contraproducente que lo haga con grandilocuencia o con un estilo demasiado rebuscado o afectado, aunque pudiera parecer literariamente elegante. Es preciso, claro está, tener un buen dominio del lenguaje: una gramática y un diccionario en el despacho de un abogado son tan necesarios como los Códigos, pero aparte de eso el estilo del abogado puede reducirse a dos requisitos: claridad y precisión. Y si hubiera que caracterizarlo con una sola palabra, yo diría: "claridad". La claridad de estilo refleja la claridad mental. Como dice Boileau en su Arte Poética: "Lo que se concibe bien se expresa claramente, y las palabras para decirlo Ilegan con facilidad". El ordenamiento lógico es muy importante en el encadenamiento de las ideas de un abogado y en la precisión con que debe presentarlas para que tengan poder persuasivo ante el tribunal donde lleva su caso. En cuanto al elemento enormemente humano que hay en el derecho penal, el derecho de familia, etc. y el ingrediente de emotividad que hay en cada asunto, hay que ser muy prudente en su manejo. En otro tiempo, no tan lejano, incluso en un procedimiento básicamente escrito, como era entre nosotros, a ese aspecto se le daba mucha importancia: golpes de efecto casi teatrales en las audiencias orales, o un recitativo interminable con acumulación de adjetivos sobre las desgracias y sufrimientos del defendido, eran moneda corriente. Hoy día, y creemos que provechosamente, eso se ha suprimido. Pero de todas maneras siempre es necesario traspasar en alguna forma al estilo del abogado este factor emocional que haga sentir que no se trata 
de un razonamiento encadenado sólo para mostrar una verdad lógica, sino que hay que resolver un caso humano. Es necesario, entonces, no prescindir de ello por completo. Incluso tiene más efecto si se usa con mesura, adecuadamente, en el momento en que debe hacerse; en una dosis no excesiva y sólo después de que se ha hecho el razonamiento lógico, no antes. A veces basta con una exposición sobria y seria del caso para hacer entender o hacer sentir lo emocional y lo humano que se encierra detrás de él. Por eso mismo es necesario que el abogado, pese a que debe compartir el estado de ánimo del cliente y sentir hondamente la responsabilidad que pesa sobre sus hombros en la defensa del caso que se le ha encomendado, debe guardar su tranquilidad, debe saber controlar sus emociones, precisamente para poder ser más eficaz en la defensa que se le ha confiado. Estoy seguro de que ninguno de ustedes se dejaría operar por un cirujano al cual se le llenaran los ojos de lágrimas y le temblara la mano por la congoja que experimenta ante el sufrimiento de ustedes como pacientes. Ustedes necesitan un cirujano, aunque sea muy amigo y los quiera mucho, que mantenga la serenidad suficiente para operar con una mano firme y con los ojos secos y fijos en lo que está haciendo. Guardando las proporciones, sucede lo mismo con el abogado. Es un grave error que muchas veces hasta grandes abogados cometen, el perder el dominio de sí mismo y el compenetrarse tanto con la angustia del cliente y con el sentimiento de injusticia, que se pierde el control de los propios actos. El cliente no necesita un abogado para que exprese esos sentimientos, que él mismo los manifiesta mejor y con más vehemencia, sino para que el abogado sepa, compartiendo esas emociones, hacer valer sus razones en la forma más serena y adecuada para hacerse comprender y llegar a un buen resultado.

En la actitud personal de todo abogado, la ética y la etiqueta son importantes. Tener la razón, o el ansia de vencer en un juicio, no autorizan jamás, ni la inmoralidad, ni las faltas de cortesía o de educación.

La relación con el juez debe estar basada en el respeto mutuo y en el principio que enunció Ángel Osorio cuando aconseja al abogado: "No pretendas ser más que el juez, pero no aceptes ser menos". El juez es un abogado, igual que nosotros, que desempeña distintas funciones, y por la ley tiene una autoridad que para resolver el caso es superior a la nuestra, pero que en el trato recíproco en el tribunal está a nuestra misma altura.

Con el colega, que siempre estará al otro lado de la barricada, mucha lealtad, el cumplimiento del compromiso, el facilitarle la resolución de sus problemas cuando por alguna razón se encuentre en una situación difícil en que necesita nuestra colaboración, porque de otra manera la vida profesional sería imposible. Nuestro oficio es por su naturaleza adversativo. Siempre estamos luchando contra un colega, y si el que es nuestro adversario en la vida profesional se transforma también en nuestro enemigo en la vida privada, en 
poco tiempo ningún abogado le hablaría a otro. Eso que a ustedes les parece sencillo, natural y hasta simpático, no es fácilmente comprendido por la gente, y no sólo por las personas de poca cultura, sino también por los que en virtud de su mayor preparación deberían entenderlo: desconfían o les parece mal si ven que el abogado a quien le han confiado la defensa de sus intereses departe amablemente en los pasillos, se ríe, conversa largo rato, o incluso va a tomarse un café con el abogado de la parte contraria. Piensan inmediatamente que su abogado no está defendiendo su asunto con suficiente energía, o aun otras cosas peores que ustedes ya podrán imaginar. Pero de todas maneras hay que sobreponerse a eso y mantener siempre con los colegas una relación de extrema lealtad, además de cultivar el respeto y la confraternidad en la vida privada, independientemente de que cada uno cumpla su deber en el proceso.

Con el cliente, lo principal es la sinceridad, tanto del cliente para con el abogado como de éste hacia aquél. El abogado debe siempre tener fe en el cliente y creer lo que éste le dice, hasta que la evidencia le demuestre que su cliente lo ha engañado, y en ese momento lo único que le cabe hacer es abandonar esa defensa. Por otra parte, el abogado le debe la franqueza de no crearle falsas esperanzas, ni mucho menos de informarle de cursos más o menos favorables del asunto encomendado, cuando ellos no son exactos, ni tratar de disimularles el cariz grave que su caso tiene o que vaya tomando. Eso el cliente lo agradece, aunque en lo inmediato pueda afligirlo, pero lo hace tomar sin duda mucha confianza con el abogado.

En el ejercicio actual de la abogacía, yo diría que las relaciones más delicadas y difíciles son con la prensa. Existe hoy día, me atrevo a decirlo, una verdadera degeneración del proceso, en particular del proceso penal. Los que ocupan las primeras páginas de los diarios o los lugares más destacados en la televisión o la radio, son generalmente procesos penales. Para usar la palabra de actualidad, se transforman en "eventos judiciales". La investigación y el juzgamiento requieren serenidad, discreción y tranquilidad, y eso se ha perdido. Una legión de periodistas profesionales, periodistas aficionados, periodistas improvisados, se precipitan sobre el acusado, sobre los policías, sobre los abogados, sobre los jueces; los testigos y peritos son acosados, son sugestionados, son inducidos a hablar y a veces hasta recompensados materialmente por conceder "entrevistas exclusivas". Prevalece en este terreno la máxima enunciada en una célebre investigación Ilevada a cabo en Inglaterra: "La necesidad de escándalo es más fuerte que la necesidad de justicia". ¿Por qué ocurre eso? Porque al público en general esos procesos le interesan. Ahí está en juego una vida, ahí está en juego la libertad, ahí se admira la maestría profesional. Eso, por supuesto, no es culpa del periodismo, pero no cabe duda de que la forma actual de tratar el proceso penal, sin negar en absoluto el derecho a una correcta información, es una influencia perniciosa sobre la justicia. Lo grave se produce cuando los 
abogados, y a veces también los jueces, ceden a la vanidad humana y se prestan para ello, en lugar de tratar de defender su tranquilidad y su función; en vez de procurar deslizarse inadvertidos detrás de las columnas del Palacio de Justicia, corren hacia las cámaras televisivas para hacerse preguntar y dejarse fotografiar o filmar.

Dentro de las obligaciones éticas, una que es común a todos los abogados, es el secreto profesional. El secreto profesional es una base indispensable para que pueda existir una defensa libre y, a nuestro juicio, aunque algunos piensan diferente, no puede ser quebrantado ni siquiera con autorización del cliente, porque uno no sabe qué presiones se han ejercido o qué malos consejos se han dado al cliente para inducirlo a pedir al abogado que prescinda del secreto profesional. Si él desea hacer público lo que nos contó en reserva, que lo haga, pero el abogado no debe hacerlo. Incluso es un quebrantamiento del secreto decir que determinada persona es nuestro cliente, aunque no se agregue nada más, a menos, naturalmente, que ya sea un hecho públicamente conocido. Pero mientras no sea del dominio público, eso no se puede decir, porque aun sin darnos cuenta nosotros, eso puede perjudicar a la persona afectada. Si un abogado se encuentra con un cliente en una reunión social, jamás debe cometer la indiscreción de hablarle de su caso; sólo si al cliente se le ocurre tocar el asunto, habrá que contestarle, pero aun así, lo mejor es tratar de cambiar de tema rápidamente. Desgraciadamente esta regla no se observa con toda la rigurosidad que sería de desear. Pocas son las veces en que un abogado quebranta un secreto profesional por un explícito deseo de perjudicar a alguien o de faltar a su deber, pero no es raro que lo haga por imprudencia o ligereza, o deseo de mostrar que se está al tanto de cosas importantes, o de alguna manera vinculado a asuntos que en esos momentos concitan la atención y están en boca de todos. Lo que ocurre, y muchos de ustedes deben conocer situaciones parecidas, es que el que recibe un secreto en confidencia absoluta, lo guarda para sí, y no se lo cuenta a nadie... más que a una sola persona, de toda su confianza, exigiéndole completa discreción y que no lo comunique a nadie. Esa persona a su vez, no se lo cuenta a nadie, absolutamente a nadie...más que a una sola persona, en quien confía por su reserva, y le pide que no se lo diga a nadie, y así, de persona de confianza en persona de confianza, termina por enterarse todo el mundo. La verdad es que la única manera de guardar un secreto es no contárselo a nadie, y punto. Eso es una regla absoluta, a la que no se debe faltar nunca. Esta obligación de discreción, aunque la ley y las tradiciones de nuestra profesión la imponen sólo al abogado mismo, trasciende a quienes prestan labores auxiliares en su estudio: procuradores, secretarias, juniors, en fin, a todos. El abogado debe velar porque ello se cumpla efectivamente, y el cliente tiene todo el derecho de exigir al abogado que impida la filtración del secreto a través de sus auxiliares. 
En fin, diremos que el abogado tiene la obligación de conocer bien y manejar a la perfección los hechos de la causa. No sólo debe conocer los textos legales, que se presume los conoce ya desde la Universidad, sino los hechos mismos que forman parte del caso. Debe saber discernir entre los que son realmente relevantes y los que carecen de importancia, manejarlos bien, saber ordenarlos y exponerlos lógicamente. Y debe presentar todo eso armado con claridad y persuasión, sin aburrir ni fastidiar al tribunal. No hay nada más triste, cuando uno asiste a un alegato, que ver cómo a un abogado se le pierden los nombres, se olvida del número de foja donde está la pieza a que quiere referirse, se confunde entre los testigos, mientras los jueces en un silencio pétreo lo miran. Se va poniendo nervioso, porque no encuentra lo que busca, y al final terminan por perdérsele las ideas. Eso ocurre en la realidad, desgraciadamente, es una cosa casi patética. De modo que nunca asuman ustedes la defensa de un caso sin estudiarlo concienzuda y profundamente.

El abogado está integrado en un sistema de administración de justicia que tiene una bases ideológico-políticas muy claras: es un sistema fundado en la filosofía liberal, que a su vez se basa en el respeto del hombre. Este sistema nos dice que no se puede condenar a nadie sin juicio, que el juicio debe ser justo, y que no hay juicio justo sin defensa para el acusado. Nuestra propia Constitución dispone literalmente que "toda persona tiene derecho a defensa jurídica en la forma que la ley señale", y que "nadie puede impedir, restringir, ni perturbar la intervención del abogado". En fin, la Constitución añade que "la ley arbitrará los medios para otorgar asesoramiento y defensa jurídica a quienes no puedan procurárselos por sí mismos". La ley otorga hoy día derecho aun al simple inculpado para designar abogado: si es acusado, se le obliga a tenerlo, y si no puede o no quiere nombrarlo, se le designa uno de oficio por el tribunal, que tiene la obligación de aceptar la defensa hasta el término de la causa, salvo que el procesado decida reemplazarlo por otro.

El abogado es un integrante del sistema judicial liberal, y el papel que se le encomienda es uno de parcialidad. El abogado tiene la prohibición de ser mentiroso, pero sí debe ser parcial, en el sentido de que el papel que se le encomienda, es decir, todo lo bueno que se pueda decir en favor de su defendido. El abogado que no hace eso no cumple con su deber, traiciona al sistema y asume el papel de juez de su defendido. El que debe mirar a la vez lo bueno y lo malo es el juez. El abogado debe ayudar a que el juez tome una buena fotografía iluminando desde un lado la escena, porque el colega contrario la va a iluminar desde el otro. El conjunto de esas luces es el que permite que el juicio sea justo y que el juez esté debidamente advertido, ilustrado, sobre todos los aspectos del asunto. El abogado en principio debe aceptar los casos que se le proponen, salvo que exista una contradicción muy grande en una situación particular, entre sus sentimientos y su deber, pero siempre considerando que 
su misión no es defender un delito, sino defender a un hombre. E incluso así, si ha sido designado de oficio, debe aceptar, debe dominar sus sentimientos y cumplir con su deber profesional. Cuanto más grave es el delito, cuánto más grave la atmósfera pública, hoy día exacerbada todavía por la multiplicación de los medios de comunicación, más grande el prejuicio público que ya existe contra el acusado y, por lo tanto, más importante, más grave y más seria es la obligación del abogado de hacerse cargo de la defensa y desempeñarla a conciencia.

Lo que hemos venido diciendo se refiere a la visión clásica del abogado, defensor de causas individuales frente a los tribunales de justicia. Más todavía: Ossorio, en "El Alma de la Toga", como el propio título lo indica, identifica al abogado con el abogado de toga, o sea, el que litiga ante los tribunales: no es para él propiamente abogado el que sólo es catedrático o solamente abogado de despacho, que atiende consultas o hace informes escritos, ni el abogado funcionario. Esa visión tiende a cambiar, y se traduce ante todo en el aumento del número de abogados. Hace unos treinta años, el número de abogados en Chile era de alrededor de 4 ó 5 mil; hoy día no hay estadísticas ciertas, pero deben ser alrededor de 15.000. Por su propia naturaleza, el número de jueces no ha aumentado tanto, pero igualmente se observa la tendencia a crear nuevos juzgados y nuevas Cortes de Apelaciones y a aumentar el número de miembros de la Corte Suprema. A ello deben añadirse todos los miembros del Ministerio Público, que si bien no son propiamente magistrados, son también abogados, y sin duda desempeñan un papel público importante encuadrado dentro del sistema de administración de justicia. Se trata de un fenómeno mundial: leemos que el número de abogados en ejercicio en París ha aumentado desde 3.000 en 1978 hasta 14.000 en la actualidad. La misma tendencia se observa en Inglaterra, en Alemania, en España, y en Italia. En el mundo hay alrededor de 4.500.000 abogados, de los cuales la quinta parte (unos 900.000) está concentrada en un solo país: Estados Unidos. Conocemos la existencia allí de las Ilamadas mega firms o firmas gigantes, con centenares de abogados, que trabajan por turnos las 24 horas del día, donde el contacto directo del abogado con el cliente es mínimo, y su gran número impide que muchos de los miembros de una misma firma siquiera se conozcan entre sí personalmente: ya no son estudios de abogados, sino verdaderas empresas jurídicas.

Este aumento en el número de abogados responde a la cantidad cada vez más creciente de personas que solicitan justicia, o para decirlo más exactamente, con un matiz que es muy importante, que esperan una solución legal y final para su problema. Esto es un saludable avance democrático, pero al mismo tiempo hace imposible resolver todos esos problemas dentro del simple esquema clásico del juez pasivo en materia civil, que sólo escucha a los abogados de las partes, o el juez inquisitivo en materia penal, preocupado de averiguar la verdad y de 
aplicar la ley imparcialmente y sin acomodos, frente a su adversario, el abogado que ejercita la defensa y a quien le basta exigir que la parte acusadora pruebe los cargos, dada la presunción de inocencia.

De ahí la tendencia muy marcada y que se observa también en nuestro país, a buscar las llamadas vías alternativas de solución de los conflictos, tanto en materia civil como en materia penal. En materia civil, citaremos sólo dos ejemplos: el auge inusitado de los arbitrajes, que aunque existentes de antigua data en la ley, fueron siempre un método excepcional de resolver los conflictos; hoy día se modifica y amplía considerablemente la procedencia del arbitraje, y se crean instituciones, oficiales o extraoficiales, bajo el amparo de los Colegios de Abogados, de las Cámaras nacionales e internacionales de Comercio, etc., dedicadas exclusivamente a proveer de servicios arbitrales, esto es, servicios de jueces ad-hoc para cada caso, pero también de mediadores o de conciliadores, en lo que era considerado una provincia exclusiva del juez, como representante de un poder del Estado. La otra muestra de esta tendencia es la importancia mucho mayor que la ley ha ido otorgando a la conciliación. Lo que era no hace tanto tiempo una posibilidad ofrecida al juez, y de la que no se hacía uso muy frecuente, ha pasado a ser obligatoria, por lo menos una vez, y facultativa para ocasiones posteriores, y se señala específicamente que el juez obrará como amigable componedor (esto es, no estará atado por la ley, lo que antes era impensable y sólo propio de una clase especial de árbitros); propondrá personalmente bases de arreglo a las partes (lo que es salir de la tradicional pasividad del juez durante el proceso civil), y tratará de obtener un avenimiento total o parcial en el litigio (esto es, su finalidad no será tanto hacer justicia, sino lograr la paz).

Este cuadro no es menos cierto en materia penal, donde podría pensarse que por la propia naturaleza del derecho punitivo, prerrogativa exclusiva del Estado y de la ley, el descubrimiento de la verdad y la aplicación inflexible de la ley no pueden ser suplidos por arreglos, avenimientos o acuerdos. Hoy ya no es así, y la tendencia se manifiesta en los sistemas jurídicos de todo el mundo: también aquí se recurre a los medios alternativos: no sólo a las medidas alternativas a la pena, que ya se habían ido abriendo camino en los últimos tiempos, sino en las medidas alternativas a la acción penal, a la prueba y a la sentencia. Son muestras de esta tendencia la bagatelización de los delitos en Alemania; la introducción de la mediación penal en Francia; del asistente de mediación en Bélgica. Lo es igualmente la paulatina desaparición del juez de instrucción, magistrado encargado de averiguar la verdad y de actuar imparcialmente en esa tarea. Lo suprimió Alemania en 1974, Italia en 1989 y los mismos sistemas francés y español van evolucionando hacia un sistema más contradictorio. En Chile ya ha sido suprimido. El Ministerio Público representa en teoría el "interés social" y este interés puede exigir a veces la renuncia total o parcial a la 
justicia absoluta (fiat justitia et pereax mundi) con tal de alcanzar la paz social, el resarcimiento de la víctima, la rapidez y abaratamiento del proceso. Nuestro Código Procesal Penal incorpora al menos las siguientes instituciones fundadas en esos principios:

(1) El Ilamado principio de oportunidad, por oposición al principio de legalidad, que obliga a investigar y sancionar todos los delitos. El Ministerio Público puede ejercer una discreción selectiva y decidir no llevar adelante una investigación si el hecho "no comprometiere gravemente el interés público", y no tuviere asignada una pena muy alta.

(2) Los acuerdos reparatorios. Proceden en los delitos por imprudencia o negligencia, lesiones menos graves o delitos patrimoniales dentro del ámbito de la disponibilidad de los bienes jurídicos (en general, cuando no ha habido violencia). Es el acuerdo entre el imputado y la víctima para compensar económicamente a ésta: si ella acepta y el juez verifica que se cumplen los requisitos legales, se dicta sobreseimiento definitivo y se termina el procedimiento.

(3) El procedimiento abreviado. Es aquél en que antes del juicio oral, el fiscal y el imputado se ponen de acuerdo para evitarlo y pedir en cambio que la sentencia se dicte por el juez de garantía sobre la base de la prueba reunida en la investigación, no en el juicio. Aquí se llega a dictar sentencia, que pudiera ser absolutoria, pero si es condenatoria, no puede imponer pena superior a la pedida por el fiscal. Es lo que se llama en el procedimiento norteamericano el plea bargaining. Y tenemos la impresión, podemos equivocarnos, de que ésta irá siendo la regla general para fallar los juicios: es más breve, más cómodo, más simple y más barato para todos, cuando el imputado ha admitido su participación y el abogado no está seguro de que en un juicio oral obtendrá una pena inferior a la pedida por el Fiscal. Ya no se trata de imponer la pena exigida por la ley, sino la que resulte socialmente más aceptable para todo el mundo.

La condición esencialmente adversativa del proceso (entre las partes, en materia civil; entre acusador y acusado, en materia penal) cambia radicalmente: todos se transforman en actores concurrentes para llegar lo más pronto posible a una solución que deje a todos contentos o al menos les otorgue lo que se ha llamado "la igualdad de la insatisfacción". Es el reconocimiento, liso y llano, de que los medios tradicionales de administrar justicia no dan abasto para satisfacer los reclamos de justicia de una masa cada vez mayor de ciudadanos. El juez no se sienta ya en el estrado para decir: "Veamos quién tiene la razón; hable y pruebe cada uno su punto de vista y yo aplicaré la ley", sino que se sienta como un verdadero moderador o mediador junto con las partes, sus abogados y sus expertos, y dice "Señores, veamos cómo podríamos terminar satisfactoriamente este conflicto. ¿Cuánto están dispuestos a ceder cada uno en sus pretensiones? Piensen en el tiempo y el costo de un juicio prolongado", o bien simplemente 
constata que la exigencia social se manifiesta satisfecha con lo que el fiscal ha propuesto y el imputado aceptado.

Hay una sutil, pero clara e innegable tendencia a sustituir uno de los fines del derecho, que es la justicia, por otro de ellos: la paz social. La justicia así entendida no será la voluntad de dar a cada uno lo suyo, sino a cada uno el mínimo con que se contente. Los Tribunales de Justicia serán Tribunales de Paz y el Poder Judicial será Poder Pacificador o Moderador.

Puede apreciarse que en este estado de cosas al abogado le corresponde también una misión muy importante y adquiere verdaderamente el carácter de auxiliar de la administración de justicia que le atribuye la ley, pero que actualmente no se percibe como tal por los jueces. Junto con los demás abogados y con los tribunales, puede proponer soluciones, salidas, alternativas que van más allá de hacer prevalecer estrictamente la ley. Estas mutaciones nos desconciertan, porque cambian la imagen tradicional del abogado. La justicia toma conciencia de que su oferta es limitada frente a una demanda potencialmente infinita y que es preciso buscar salidas que no sean el simple atochamiento, ya que la justicia también tiene un costo, y que la justicia excesivamente lenta deja de serlo. En suma, el crecimiento del derecho causado por las demandas sociales trastorna las profesiones que se hacen cargo de ellas. ¿Qué pensar de esta evolución? Sin duda estamos girando un codo importante en la historia y la sociología del derecho, en que la administración de justicia y la aplicación de la ley clásicas ya no pueden tratar de modo idéntico la masa y la complejidad de los conflictos. Piénsese que en nuestro derecho todavía vigente se someten al mismo procedimiento el hurto de una bicicleta y los complejísimos procesos financieros por quiebras de grandes firmas y fraudes contables. La administración de justicia debe ser portavoz sereno y reflexivo del estado moral de la sociedad en que se desempeña.

El abogado debe estar atento a estos cambios y así tendrá mañana en la sociedad el puesto indispensable que ha tenido hace siglos y que tiene hasta hoy. Y debe estar dispuesto a luchar, como dice Couture: luchar por la justicia, luchar por la paz y sobre todo, por la libertad, sin la cual no hay justicia, no hay paz, y a la larga ni siquiera orden.

Gracias, señor Rector y autoridades universitarias, por la oportunidad que me han brindado de compartir con ustedes el comienzo de esta jornada de trabajo con tan buenos augurios; gracias, estimados amigos, por la atención que han prestado a estos comentarios; ojalá que mediten sobre los conceptos que me han escuchado y que encaminen con paso firme el resto de sus vidas por la senda del derecho.

Gracias a todos. 
